\title{
Modelagem de Fluxo e Análise do Potencial Hídrico de Aquífero Aluvial no Semiárido de Pernambuco
}

\author{
Adriano Luiz Normandia Monteiro ${ }^{1}$, Abelardo Antônio de Assunção Montenegro ${ }^{1}$, \\ Suzana Maria Gico Montenegro ${ }^{2}$ \\ ad_normandia@hotmail.com; abelardo.montenegro@yahoo.com.br; suzanam@ufpe.br
}

Recebido: 12/06/13 - revisado: 07/11/13 - aceito: 07/03/14

\section{RESUMO}

Este trabalho foi desenvolvido em vale aluvial utilizado para pequena irrigação, com o objetivo de avaliar seu potencial hídrico na condição corrente de explotação e a relevância da interação rio-aquífero, mesmo em período seco. Utilizando-se o software Visual MODFLOW, foram avaliados os fluxos e a distribuição do potencial hídrico no vale, considerando o uso e ocupação do solo. Para calibração e validação do modelo, admitiu-se que as extrações do aquífero seguiram critério agronômico, baseado no consumo hídrico das culturas. Foram avaliados cenários com diferentes frações de lixiviação (de 20\%, 50\% e 100\%) para investigar o efeito do acréscimo de extrações na potenciometria do aquífero, e sua influência no rebaixamento do lençol, principalmente durante o período de recessão hídrica. Além dos fluxos difusos na superfície (recarga e evaporação), foram consideradas contribuições oriundas da bacia hidrográfica circunvizinha. Constatou-se a importância da interação rio-aquífero nos seus níveis potenciométricos, podendo-se verificar que o aquífero aluvial está submetido a elevadas taxas de recarga, de modo que as taxas de bombeamento aplicadas não estão colocando em risco a sua sustentabilidade.

Palavras-chave: Agricultura irrigada, água subterrânea, interação rio-aquífero.

\section{INTRODUÇÃOO}

A região semiárida Nordestina possui regime irregular de chuvas, e elevada taxa de evapotranspiração, requerendo irrigação para uma adequada produção agrícola. $\mathrm{O}$ fornecimento hídrico, em sua maioria, é oriundo de mananciais superficiais intermitentes e de fontes de águas subterrâneas escassas (SANTOS et al. 2009).

Várias áreas de assentamento no Nordeste dependem da irrigação em pequena escala para o desenvolvimento da agricultura. Os aluviões apresentam potencial para uso na irrigação em regime familiar. Dependendo das condições locais de salinidade de água e solo, o manejo da irrigação nestas áreas depende de técnicas de controle como a adoção de frações de lixiviação. Uma vez que essa técnica implica em incremento nas taxas de bombeamento, é importante avaliar o seu impacto no rebaixamento dos níveis potenciométricos.

${ }^{1-}$ Departamento de Tecnologia Rural/UFRPE

${ }^{2}$ - Departamento de Engenharia Civil/UFPE
A potenciometria dos aquíferos aluviais é influenciada pela conexão hidráulica com as águas de superfície, mas as suas interações são difíceis de observar e medir por métodos tradicionais. Vários estudos foram desenvolvidos no contexto da relação rio-aquífero. Comparando cenários potenciométricos, Gomes \& Frischkorn (2009) observaram forte influência da interação rio-aquífero em aluvião do Nordeste do Brasil. Fontes Júnior et al. (2012) verificaram maior estabilidade temporal dos níveis piezométricos em locais próximos ao riacho principal de um vale aluvial no semiárido pernambucano, o mesmo adotado neste estudo.

As interações entre rio e aquífero dependem principalmente da diferença de carga hidráulica no rio e no aquífero e das características físicas do leito do rio (RASSAM, 2011). Quando o nível potenciométrico do aquífero está próximo à superfície, o escoamento do rio pode ser parcialmente controlado pelo aquífero (RUSHTON, 2007). Neste casos, os rebaixamentos resultantes do bombeamento das águas subterrâneas podem impactar o escoamento superficial (SOPHOCLEOUS, 2002).

Burte et al. (2009) ressaltam a importância da modelagem computacional na gestão de bacias 
hidrográficas, especialmente da exploração de aquíferos aluviais do semiárido, particularmente para irrigação e abastecimento doméstico. Pode-se analisar cenários de gestão de águas e seus impactos sobre a disponibilidade de recursos hídricos, de modo a não comprometer a sustentabilidade de um aquífero.

Um modelo amplamente utilizado para simular fluxo de água subterrânea em meios porosos e que permite a investigação do comportamento de interação entre rio e o aquífero é o MODFLOW. Tal modelo utiliza resolução numérica por Diferenças Finitas da equação diferencial do fluxo subterrâneo (MCDONALD \& HARBAUGH, 1984), sendo amplamente aplicado no estudo da hidrodinâmica de aquíferos de diferentes geometrias e graus de confinamento, sob a influência de bombeamento intensivo.

Em estudos de aplicação de práticas econômicas da irrigação, Xu et al. (2009) desenvolveram e implementaram uma metodologia integrando o modelo MODFLOW a uma ferramenta de Sistema de Informação Geográfica para quantificar o efeito da atividade humana em região de clima árido e semiárido, permitindo avaliar os rebaixamentos produzidos.

Lima et al. (2007) realizaram estudo experimental e teórico da interação entre o rio e aquífero aluvial do semiárido brasileiro para investigar a sua dinâmica potenciométrica. Nesse trabalho foi utilizado um modelo analítico de predição para estimar as propriedades hidráulicas do aquífero e do leito do rio, o qual foi comparado com o modelo MODFLOW que, embora tenha apresentado subestimativas em situações de elevados potenciais hidráulicos, comportou-se adequadamente nas previsões numéricas.

Utilizando o modelo MODFLOW em aquífero aluvial do semiárido cearense, Gomes \& Frischkorn (2009) identificaram zonas de maior rebaixamento, resultantes de elevada explotação de água para irrigação, e investigaram o efeito da perenização de rio na potenciometria do aquífero.

Batista et al. (2011) aplicaram o modelo MODFLOW em bacia sedimentar costeira da Paraíba para subsidiar a gestão conjunta de águas superficiais e subterrâneas. O estudo permitiu observar que o aquífero encontra-se intensamente explotado, requerendo adoção de medidas de gestão dos recursos hídricos para garantir sustentabilidade das águas subterrâneas na bacia.

Este trabalho teve como objetivo analisar a dinâmica das águas subterrâneas em vale aluvial, no semiárido nordestino, onde é praticada agricultura irrigada em escala familiar. Investigou-se o impacto de diferentes cenários de bombeamento na sustentabilidade hídrica do perímetro irrigado, utilizandose modelagem.

\section{MATERIAL E MÉTODOS}

\section{Área de Estudo}

A Fazenda Nossa Senhora do Rosário está localizada no município de Pesqueira-PE, Agreste Pernambucano, a $228 \mathrm{~km}$ da cidade de Recife. Com área de aproximadamente 110 ha, suas terras distribuem-se em estreita faixa ao longo do terraço aluvial do Rio Ipanema, e são limitadas por áreas de encostas do embasamento cristalino. Na Fazenda existem aproximadamente 60 ha irrigados, cultivados por cerca de 50 famílias de agricultores, que utilizam a água subterrânea para a pequena agricultura irrigada de base familiar. As coordenadas geográficas são $08^{0} 10^{\prime} 25^{\prime}$ 'S, $35^{0} 11^{\prime} 25^{\prime \prime} \mathrm{W}$, de latitude e longitude, respectivamente, estando a $650 \mathrm{~m}$ de altitude (MONTENEGRO \& MONTENEGRO 2006).

O aquífero aluvial é raso, com profundidade média de $10 \mathrm{~m}$, possuindo cerca de $15 \mathrm{~km}$ de extensão e $300 \mathrm{~m}$ de largura. Na área de interesse, o aluvião possui cerca de $2,5 \mathrm{~km}$ de extensão, inserido na Bacia do Riacho Mimoso de área contribuinte de 124,36 km² (BASTOS et al., 2009).

A condição climática da área de estudo é semiárida quente tipo Estepe, BSsh segundo a classificação de Köppen. Nessa área ocorrem precipitações médias anuais da ordem de $730 \mathrm{~mm}$, concentradas nos meses abril a agosto. A temperatura média mensal oscila entre de 20 e $30^{\circ} \mathrm{C}$.

\section{Uso corrente}

Os solos do vale aluvial são intensamente cultivados com irrigação. A principal prática agrícola é a olericultura, destacando-se tomate, repolho, cenoura, e pimentão, e fruticultura: maracujá e banana. Encontram-se também na área capins de corte, para pecuária leiteira. As áreas de encosta são geralmente usadas como pastagens, ou cobertas por formações secundárias arbustivas (RIBEIRO \& CORRÊA, 2001). Na irrigação são utilizados 4 poços públicos tipo Amazonas com ponteiras radiais e 30 cacimbões para irrigação, segundo Montenegro (1997). Os cultivos estão distribuídos em lotes de até 1 hectare, conduzidos por agricultores familiares. 


\section{Dados agroclimatológicos}

Os dados de pluviometria mensal utilizados referentes ao município de Pesqueira foram fornecidos pelo Instituto Nacional de Meteorologia (INMET), bem como em pluviômetros instalados no vale aluvial, durante os trabalhos de Blackburn (2002) e Santiago et al. (2004).

A evapotranspiração potencial foi estimada através de Tanque Classe $\mathrm{A}$, instalado na área, a partir do coeficiente de Tanque, em função da velocidade média do vento e da umidade relativa do ar, obtendo-se Coeficiente de Tanque de 0,75 (DOORENBOS \& PRUITT, 1997).

\section{Monitoramento do aquífero}

As linhas potenciométricas do aquífero foram avaliadas através de piezômetros e poços de observação distribuídos ao longo da área, monitorados mensalmente.

\section{Condutividade hidráulica}

Montenegro (1997) realizou detalhado estudo de caracterização da condutividade hidráulica da zona saturada do vale, instalando 65 piezômetros e realizando "slug test" em cada um deles. As condutividades hidráulicas variam de $0,097 \mathrm{~m} \mathrm{~d}^{-1}$ a 125,01 m.d ${ }^{-1}$, com média aritmética de 23,39 m.d $\mathrm{d}^{-1} \mathrm{e}$ geométrica de $4,83 \mathrm{~m}^{-1} \mathrm{~d}^{-1}$, conforme apresentado por Fontes Júnior et al. (2012).

\section{Estimativa das vazões bombeadas nos poços e nos lotes irrigados}

As taxas explotadas diariamente tanto pelos poços públicos como pelos cacimbões são bastante variáveis, tanto espacialmente quanto ao longo do ano. Para efeito deste estudo, as explotações foram estimadas segundo critério agronômico, considerando o consumo efetivo, de acordo com a necessidade hídrica das culturas em uso, para atender a demanda dos lotes irrigados, vinculados a cada agricultor. A Tabela 1 apresenta alguns valores característicos de vazão para os lotes, onde se encontram as principais culturas irrigadas. Para elaboração desta tabela, realizou-se cadastramento de campo e georeferenciamento das áreas cultivadas, que foram locadas no mapa da área, apresentado na Figura 1.

Observa-se em campo uma diversidade de culturas que se alternam ao longo dos anos. Embora ocorra uma rotação de culturas no caso daquelas de ciclo curto, as necessidades hídricas por unidade de área tendem a não variar significativamente. Para este estudo, adotou-se coeficiente de cultura máximo para as olerícolas em geral. A avaliação da vazão a ser extraída por bombeamento foi realizada através da Eq. (1) a seguir:

$$
Q=\left[\left(E T_{0} \times K c_{\text {máx }}\right)-(P)\right] \times \text { Área } / \Delta t
$$

Em que:

$\mathrm{Q}=\operatorname{Vazão}\left[\mathrm{L}^{3} \mathrm{~T}^{-1}\right]$

$\mathrm{ET}_{0}=$ evaporação potencial $\left[\mathrm{LT}^{-1}\right]$;

$\mathrm{Kc}_{\text {máx }}=$ Coeficiente de cultura máximo durante seu período de desenvolvimento $\left[\mathrm{L}^{0}\right]$;

$\mathrm{P}=$ precipitação $\left[\mathrm{LT}^{-1}\right]$;

Área = área irrigada pelo poço amazonas $\left[\mathrm{L}^{2}\right]$; $\Delta \mathrm{t}=$ intervalo de tempo de irrigação[T] .

\section{Modelagem Numérica}

O modelo utilizado foi o Visual MODFLOW (GUIGUER \& FRANZ 1996). Este tem como base o código numérico MODFLOW, desenvolvido por MacDonald \& Harbaugh (1984) do USGS (Serviço Geológico dos Estados Unidos).

As principais vantagens deste programa são a rapidez e facilidade para simular diferentes cenários após a definição do modelo conceitual, a adequada interação com o usuário, e as ferramentas próprias para calibração como o MODINV (OLSTHOORN, 1999; WINSTON, 1999).

O fluxo saturado em meios porosos pode ser expresso pela seguinte equação diferencial (Eq. 2).

$\frac{\partial}{\partial x}\left(h \cdot K_{x} \frac{\partial h}{\partial x}\right)+\frac{\partial}{\partial y}\left(h \cdot K_{y} \frac{\partial h}{\partial y}\right)+W(x, y, t)=S \frac{\partial h}{\partial t}$

em que:

h - carga piezométrica (L);

$\mathrm{K}_{\mathrm{x}}, \mathrm{K}_{\mathrm{y}}$ - componentes principais da condutividade hidráulica $\left(\mathrm{LT}^{-1}\right)$;

$\mathrm{S}$ - coeficiente de armazenamento $\left(\mathrm{L}^{-1}\right)$;

$\mathrm{W}$ - Fontes ou sumidouros de água $\left(\mathrm{L}^{3} \mathrm{~T}^{-1} \mathrm{~L}^{-3}=\mathrm{T}^{-1}\right)$;

$\mathrm{X}$ e Y- coordenadas de posição (L);

$\mathrm{t}$ - tempo $(\mathrm{T})$

Para a condição de variação instantânea do nível do rio relativo ao nível de água do aquífero adjacente, a r azão entre a mudança na altura da 
Modelagem de Fluxo e Análise do Potencial Hídrico de Aquífero Aluvial no Semiárido de Pernambuco

Tabela 1 - Vazão para lotes irrigados, para os principais cultivos da Fazenda

\begin{tabular}{cccccc}
\hline Ordem dos lotes & Poço Amazonas & Cultura & $\begin{array}{c}\text { Kc } \\
\text { máximo }\end{array}$ & $\begin{array}{c}\text { Q média } \\
\mathrm{m}^{3} \cdot \text { dia }^{-1}\end{array}$ & $\begin{array}{c}\text { Q máxima } \\
\mathrm{m}^{3} \cdot \text { dia }^{-1}\end{array}$ \\
\hline 1 & CA1 & Pimenta & 0,95 & 12,64 & 26,25 \\
2 & CA2 & Banana & 1,25 & 9,94 & 20,92 \\
3 & CA3 & Cenoura/Pimentão & 1 & 10,89 & 22,65 \\
4 & CA4 & Pimentão & 0,95 & 12,33 & 25,60 \\
5 & CA5 & Repolho & 1 & 6,72 & 13,96 \\
6 & CA6 & Banana & 1,25 & 15,17 & 30,50 \\
7 & CA8 & Tomate & 1,05 & 13,39 & 27,38 \\
8 & CA10 & Banana & 1,25 & 15,86 & 32,41 \\
9 & CA 16 & Pinha & 1,25 & 9,37 & 19,99 \\
10 & CA 19 & Repolho & 1,05 & 9,07 & 18,53 \\
11 & CA 21 & Tomate & 1,05 & 13,07 & 28,53 \\
12 & CA 17 & Cenoura & 1,05 & 19,76 & 43,35 \\
13 & CA9 & Jerimum & 1,05 & 7,84 & 16,04 \\
14 & CA20 & Banana & 1,25 & 30,22 & 63,64 \\
15 & CA22 & Banana & 1,25 & 19,28 & 40,60 \\
16 & CA13 & Banana & 1,25 & 25,69 & 54,10 \\
17 & P4 & Tomate & 1,05 & 57,52 & 117,62 \\
18 & P3 & Beterraba & 1,05 & 20,91 & 42,77 \\
19 & P2 & Banana & 1,25 & 84,63 & 178,22 \\
20 & P1 & Goiaba & 1,25 & 48,97 & 101,84 \\
21 & CA24 & Cenoura & 1,05 & 11,38 & 23,42 \\
\hline
\end{tabular}

Kc - coeficiente de cultura máximo (necessidade hídrica das culturas) Fonte: Doorenbos \& Pruit (1997)

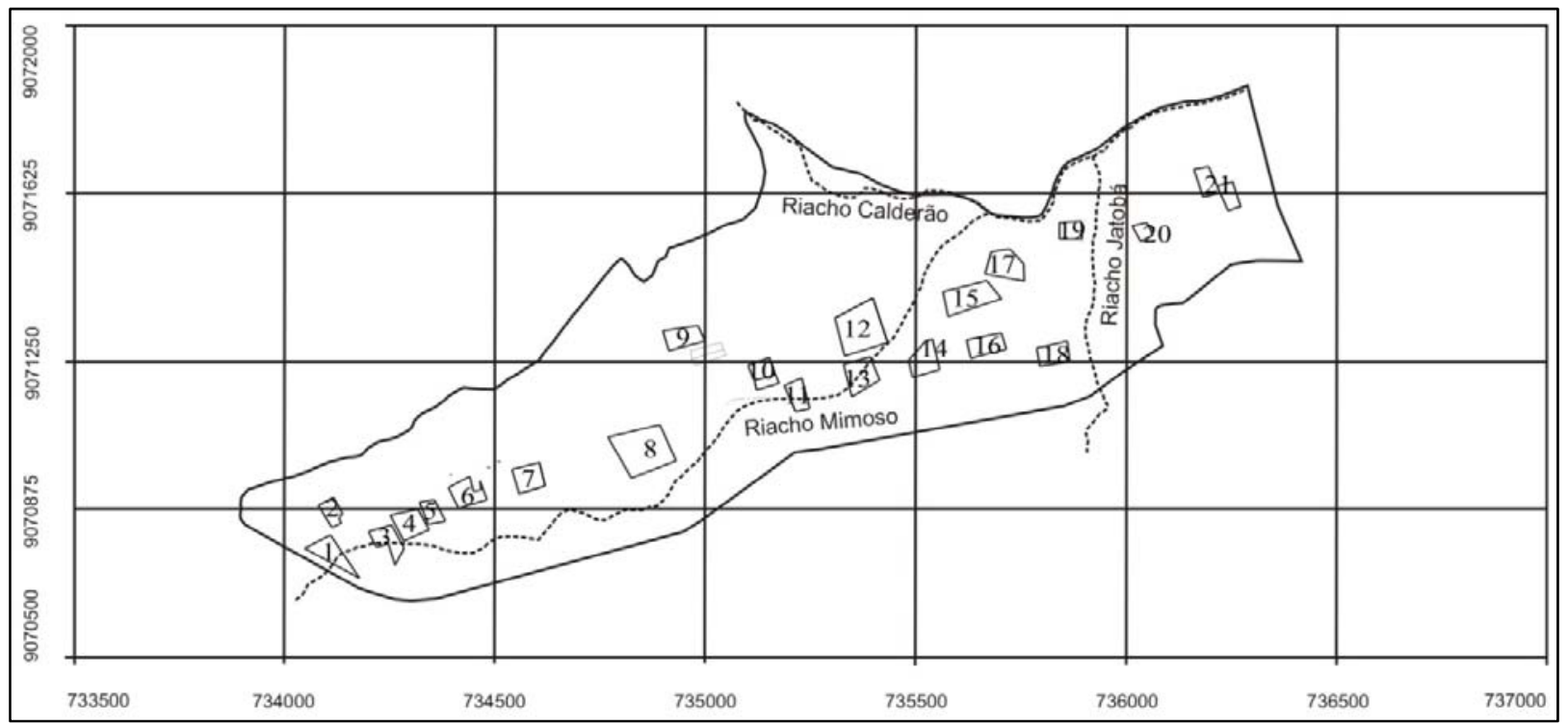

Figura 1 - Esquema típico, representando a geometria do sistema aluvial, e a localização dos lotes

água no aquífero em uma dada localização $(\mathrm{x}, \mathrm{z})$ e em um dado tempo (t) e a variação instantânea no $h_{D}(x, z, t)=\frac{h_{i}-h(x, z, t)}{c}$ nível da água do rio, considera-se (Eq. 3): 


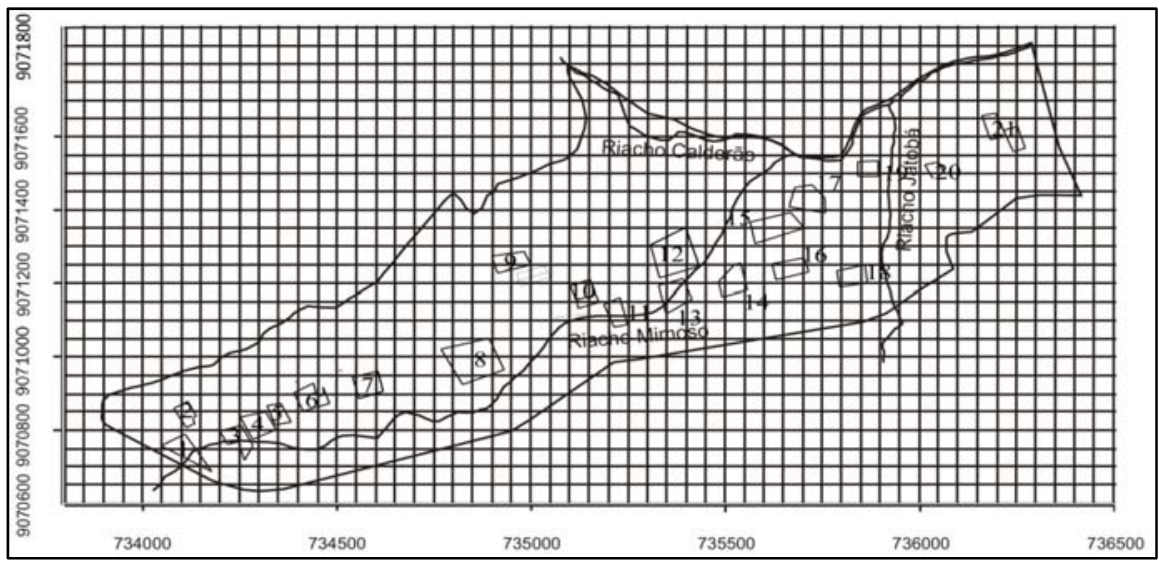

Figura 2. - Discretização da malha da fazenda Nossa Senhora do Rosário

Tabela 2 - Parâmetros físicos considerados e seus valores

\begin{tabular}{lll}
\hline Parâmetro & Valor & Unidade \\
\hline Condutividade hidráulica geral & 1 & $\mathrm{~m} \cdot \mathrm{d}^{-1}$ \\
Porosidade efetiva & 0.3 & - \\
Coeficiente de armazenamento & 0.3 & - \\
Espessura da camada saturada $\mathrm{h}$ & 10 & $\mathrm{~m}$ \\
Armazenamento específico Ss $(\mathrm{Ss}=\mathrm{S} / \mathrm{h})$ & 0.03 & $1 . \mathrm{m}^{-1}$ \\
\hline
\end{tabular}

Em que: $\mathrm{h}_{\mathrm{D}}(\mathrm{x}, \mathrm{z}, \mathrm{t})$ é a solução adimensional da resposta de grau unitária, c é a mudança instantânea no nível de água do rio $\left(\mathrm{h}_{\mathrm{i}}-\mathrm{h}_{0}\right), \mathrm{h}_{\mathrm{i}}$ é o nível inicial de água no sistema rio-aquífero e $\mathrm{h}_{0}$ é o nível de água do rio após a mudança instantânea.

Para representar a área de estudo, foi adotada uma malha regular de $50 \mathrm{~m}$ x $50 \mathrm{~m}$ (linha $\mathrm{x}$ coluna), gerando 2100 células. A malha foi refinada para melhor reproduzir os limites do aquífero, como mostra a Figura 2. Utilizou-se valores mensais como discretização temporal. Uma vez calibrado o modelo, avaliou-se o comportamento do nível potenciométrico, ao se adotar frações de lixiviação, correspodendo à lâmina de drenagem ou de lavagem aplicada ao solo, de $20 \%, 50 \%$ e $100 \%$, representando uma lâmina extra no manejo da irrigação, em três setores da fazenda.

O parâmetro hidrogeológico da área de estudo desenvolvidas na calibração do Visual modflow foi o de armazanamento. A Tabela 2 apresenta os principais parâmetros físicos adotados na simulação.

\section{Critérios para fluxos difusos na superfície}

Adotou-se fator de $25 \%$ para inicializar a recarga direta oriunda da precipitação pluviométrica, assumindo-se que a irrigação não gerava recar- ga. No tocante à evaporação do lençol, utilizou-se um fator de $20 \%$ da evapotranspiração potencial da região. Estes potenciais foram estabelecidos com base em simulações numéricas procedidas por Montenegro (1997), e posteriormente validados neste trabalho.

Para início das simulações $(\mathrm{t}=0)$, foi tomado como referência o dia 1 de julho de 1995. As leituras de campo do nível d' água dos piezômetros ao longo da área seguiram sistemática mensal, com falhas no ano de 1997.

A calibração foi desenvolvida sobre as taxas de recarga, até o dia 1500. Tempos posteriores ao dia 1500 foram considerados como fase de validação do modelo, que se desenvolveu até o dia 2725. Ressalte-se que as condutividades hidráulicas foram mantidas conforme medições de campo.

Durante os períodos de precipitações mais significativas, verificou-se numericamente que a área de estudo apresenta forte influência de recarga proveniente de elevações laterais, além de recarga de base das bacias circunvizinhas, que são as bacias do Ipanema e Jatobá a Norte e a Sul, respectivamente. Assim, como condição de recarga lateral, atribuiu-se uma recarga adicional de contribuição à recarga total nos períodos mais chuvosos, apresentada nas Tabelas 3, 4 e 5, representada esquematicamente na 
Tabela 3 - Valores estimados para recarga adicional nos limites Norte e Sul

\begin{tabular}{lccccc}
\hline & $\mathrm{km}^{2}$ & $\mathrm{~N}^{\circ}$ células & $\begin{array}{c}\text { Comprimento da célula } \\
(\mathrm{m})\end{array}$ & $\begin{array}{c}\text { Comprimento da célula } \\
(\mathrm{m})\end{array}$ & $\begin{array}{c}\text { área faixa } \\
\left(\mathrm{m}^{2}\right)\end{array}$ \\
\hline Norte & $49.79^{*}$ & 72 & 50 & 50 & 180000 \\
Sul & $13.7^{* *}$ & 64 & 50 & 50 & 160000 \\
\hline
\end{tabular}

*Área da Bacia do Ipanema (Norte)

** Área da Bacia do Jatobá e vizinhanças (Sul)

Tabela 4 - Recarga adicional do Limite Norte

\begin{tabular}{lccccc}
\hline Mês & Dia Inicial & Dia Final & ppt total $(\mathrm{m})$ & $25 \%$ ppt $(\mathrm{m})$ & Rec extra $(\mathrm{m})$ \\
\hline $01 / \mathrm{Abr} / 96$ & 276 & 306 & 0,1816 & 0,00151 & 0,042 \\
$01 / \mathrm{Mai} / 96$ & 306 & 337 & 0,1657 & 0,00134 & 0,037 \\
29/Dez/99 & 1643 & 1669 & 0,1423 & 0,00137 & 0,038 \\
24/Jan/00 & 1669 & 1690 & 0,1340 & 0,00160 & 0,044 \\
14/Fev/00 & 1690 & 1727 & 0,0710 & 0,00048 & 0,013 \\
22/Mar/00 & 1727 & 1751 & 0,0770 & 0,00080 & 0,022 \\
15/Abr/00 & 1751 & 1781 & 0,0834 & 0,00069 & 0,019 \\
15/Jan/01 & 2026 & 2057 & 0,0850 & 0,00069 & 0,019 \\
15/Abr/01 & 2116 & 2146 & 0,0770 & 0,00064 & 0,018 \\
15/Dez/01 & 2360 & 2391 & 0,1600 & 0,00129 & 0,036 \\
15/Jan/02 & 2391 & 2422 & 0,1285 & 0,00104 & 0,029 \\
\hline
\end{tabular}

ppt total - precipitação total ocorrida no mês de recargas efetivas,.

$25 \%$ ppt $-25 \%$ da precipitação total ocorrida no mês

Rec extra - recarga extra calculada

Tabela 5 - Recarga adicional do Limite Sul

\begin{tabular}{lccccc}
\hline Mês & Dia Inicial & Dia Final & ppt total $(\mathrm{m})$ & $25 \%$ ppt $(\mathrm{m})$ & Rec extra $(\mathrm{m})$ \\
\hline $01 / \mathrm{Abr} / 96$ & 276 & 306 & 0,1816 & 0,00151 & 0,013 \\
$01 / \mathrm{Mai} / 96$ & 306 & 337 & 0,1657 & 0,00134 & 0,011 \\
29/Dez/99 & 1643 & 1669 & 0,1423 & 0,00137 & 0,012 \\
24/Jan/00 & 1669 & 1690 & 0,134 & 0,00160 & 0,014 \\
14/Fev/00 & 1690 & 1727 & 0,071 & 0,00048 & 0,004 \\
22/Mar/00 & 1727 & 1751 & 0,077 & 0,00080 & 0,007 \\
15/Abr/00 & 1751 & 1781 & 0,08314 & 0,00069 & 0,006 \\
$15 / \mathrm{Jan} / 01$ & 2026 & 2057 & 0,085 & 0,00069 & 0,006 \\
$15 / \mathrm{Abr} / 01$ & 2116 & 2146 & 0,077 & 0,00064 & 0,005 \\
15/Dez/01 & 2360 & 2391 & 0,16 & 0,00129 & 0,011 \\
15/Jan/02 & 2391 & 2422 & 0,1285 & 0,00104 & 0,009 \\
\hline
\end{tabular}

ppt total - precipitação total ocorrida no mês de recargas efetivas,.

$25 \%$ ppt $-25 \%$ da precipitação total ocorrida no mês

Rec extra - recarga extra calculada

Figura 3. Assumiu-se que esta recarga atinge o aquífero ao longo da interface entre o embasamento aflorante e o vale, testou-se valores para tal recarga, adotando-se um fator de contribuição de área das bacias laterais para o aquífero, com base nos níveis potenciométricos medidos.
Considerando que o aluvião em estudo tem dimensão longitudinal uma ordem de grandeza superior à dimensão transversal, a condutividade hidráulica foi inserida em faixas transversais, apresentadas na Figura 4, de acordo com a média geométrica dos valores estimados nos testes dos piezômetros localizados em cada seção. 


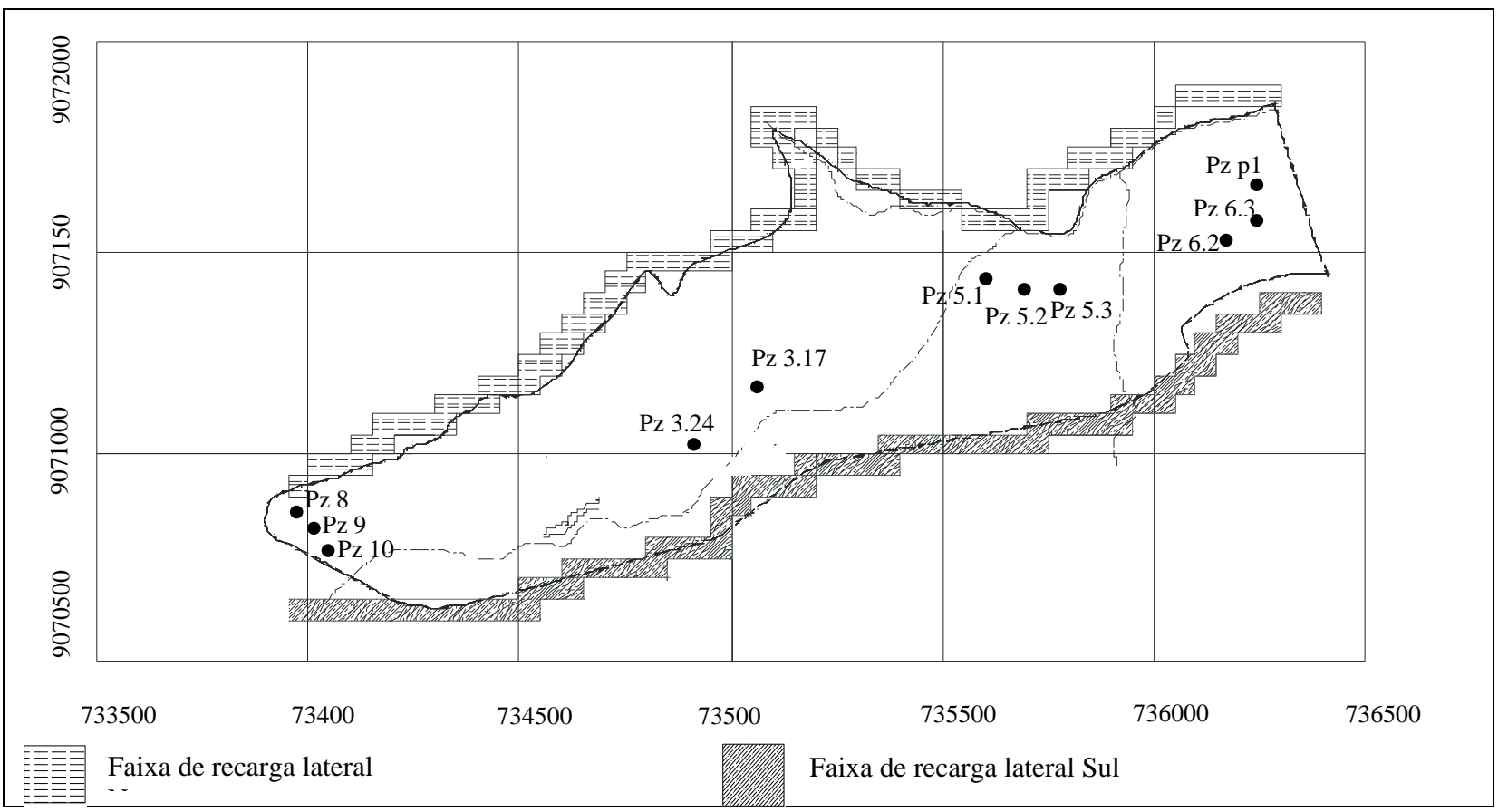

Figura 3 - Vista do vale da Fazenda com faixas de recarga adicional (condição de contorno de fluxo especificado) e dos principais piezômetros

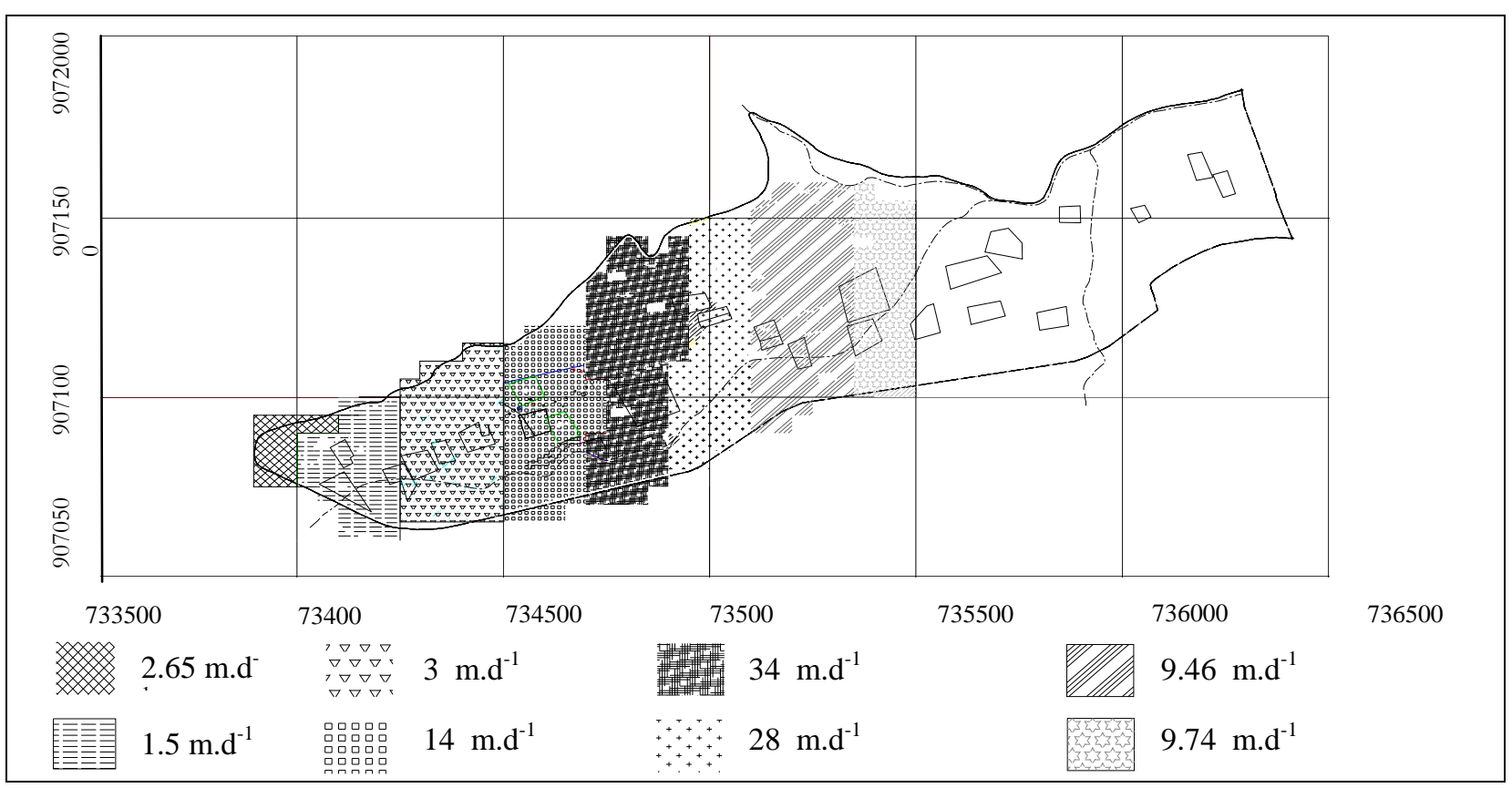

Figura 4 - Faixas de condutividade hidráulica média ao longo da Fazenda Nossa Senhora do Rosário (Região em branco com condutividade hidráulica igual a 1 m.d ${ }^{-1}$ )

Para o contorno de oeste e leste, estabeleceu-se condição de contorno com carga variável tendo como referência os piezômetros mais próximos destas bordas. 


\section{Inserção do riacho}

Para simular a influência do riacho que atravessa longitudinalmente o vale na potenciometria do aquífero, considerou-se um contorno tipo Rio utilizando a subrotina RIVER do MODFLOW, a partir da leituras de piezômetros instalados em trechos do riacho, além de piezômetros próximos a sua margem, adotando-se variação piezométrica destes, e produzindo cargas potenciométricas de montante a jusante. Foram utilizados valores de condutividade hidráulica avaliados a partir de seções transversais de piezômetros instalados ao longo do leito do riacho.

\section{Avaliação do modelo}

De modo a comparar os resultados obtidos a partir da aplicação do modelo com os experimentais, foram utilizados dois critérios estatísticos para a análise dos resultados simulados: erro quadrado médio (EQM) Eq. 4 conforme recomendado por Arbat et al. (2008) e o índice D de ajuste do modelo Eq. 5, definido por Willmot (ALVES et al. 2012).

$$
\begin{aligned}
& E Q M=\sqrt{\left(\frac{\sum\left(P_{i}-O_{i}\right)^{2}}{n}\right)} \times \frac{100}{\bar{O}} \\
& D=1-\left(\frac{\sum\left(P_{i}-O_{i}\right)^{2}}{\left.\sum\left(\left|P_{i}-\bar{O}\right|+\left|O_{i}-\bar{O}\right|\right)\right)}\right)
\end{aligned}
$$

Em que: Pi corresponde aos valores calculados pelo modelo; Oi aos valores observados experimentalmente, e $\bar{O}$ a média dos valores experimentais.

\section{RESULTADOS E DISCUSSÃO}

O comportamento do lençol freático é semelhante ao longo do eixo longitudinal do vale aluvial, respondendo hidrologicamente a eventos de precipitação, tanto por recarga distribuída direta, quanto pela contribuição a nível de bacia hidrográfica, através de recarga lateral.

As Figuras 5 e 6 apresentam a flutuação do lençol freático nos piezômetros no contorno de montante e área central do aluvião, com valores observados em campo e calculados por modelagem numérica. Os gráficos da esquerda apresentam modelagem numérica na ausência da condição de interface entre o aquífero e o riacho, e os gráficos da direita, na presença. De uma forma geral, a tendência do movimento da água subterrânea segue a pendente topográfica, que vai dos piezômetros 8, 9, 10 e 11 , localizados a montante da fazenda, aos piezômetros 6.1, 6.2 e 6.3, no contorno de jusante.

A simulação realizada na presença e na ausência do contorno do riacho apresentou comportamento semelhante para os piezômetros 8, 10 e 11, representados pelas Figuras 5A e 5B. Tal situação se deve ao fato destes piezômetros estarem próximos ao contorno Oeste, sendo fortemente influenciados pela condição de contorno adotada.

O comportamento dos piezômetros $3.17 \mathrm{e}$ 3.24, 5.1, 5.2 e 5.3 nas simulações, em termos médios, reflete a sazonalidade do aquífero, porém tendem a superestimar cargas na recessão, e a subestimar levemente as cargas no período de recuperação dos níveis (Figuras 5C e 6E), na ausência do contorno "rio".

Para os piezômetros localizados no contorno de jusante da Fazenda, como é o caso dos $\mathrm{Pz} 6.1$ e 6.2, verifica-se maior dinâmica do piezômetro $\mathrm{P} 1$, por se situar próximo a poço público que atende um grande número de agricultores, e extensa área de irrigação (área comunitária da Fazenda). Novamente, deve-se ressaltar que as flutuações produzidas pelas simulações são similares às observadas, embora haja uma subestimativa nas cargas simuladas, em alguns períodos, quando não se considera a presença do rio.

Embora observado o mesmo comportamento em reproduzir eventos de recarga, entre os valores medidos e calculados, segundo Borsi et al. (2012) e Furman (2008), simulações podem ser refinadas por meio de modificações no código do MODFOW acoplando fluxo de superfície e subterrâneo em permitir a resolução da equação de $\mathrm{Ri}$ chards em partes selecionadas no domínio do modelo. Neste estudo, tais refinamentos não foram adotados.

O modelo apresentou simulações adequadas a realidade para fluxo de água subterrâneo e concordando com Panagopoulos (2012), fornece uma representação suficiente das condições de campo e pode ser utilizado como uma ferramenta de planejamento de estratégias de gestão da água em ambientes semelhantes.

Observa-se a influência da inserção do rio nas cargas simuladas, produzindo manutenção da recarga piezométrica, bem como drenagem do aquifero. Tal influência é salientada em trabalho realizado por Arantes et al. (2006), em estudo de carac- 


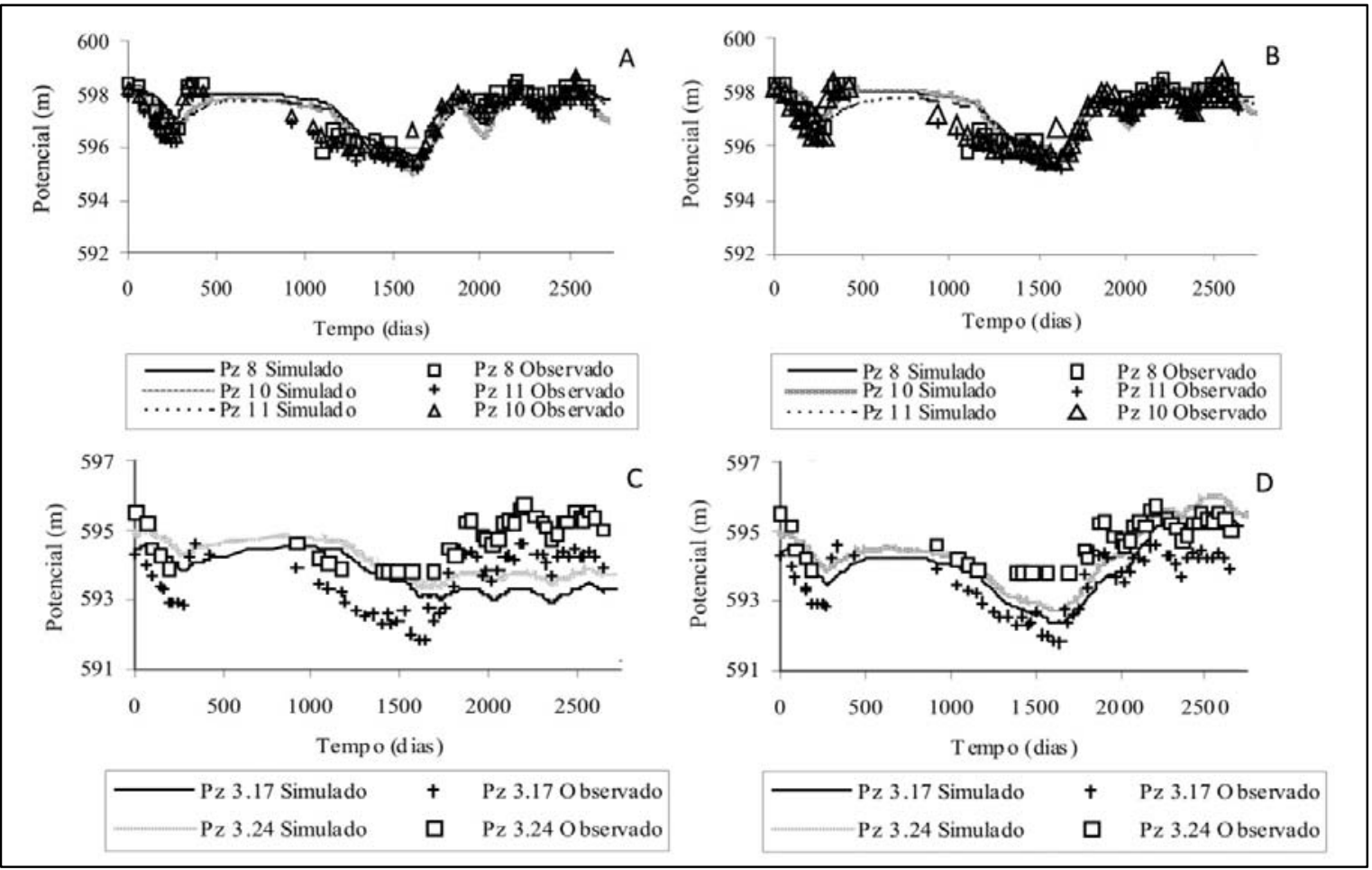

Figura 5 - Potenciometrias simuladas e observadas na face oeste do aluvião para os piezômetros sem a inserção do riacho (A e C) e na presença da contribuição hídrica do riacho (B e D)

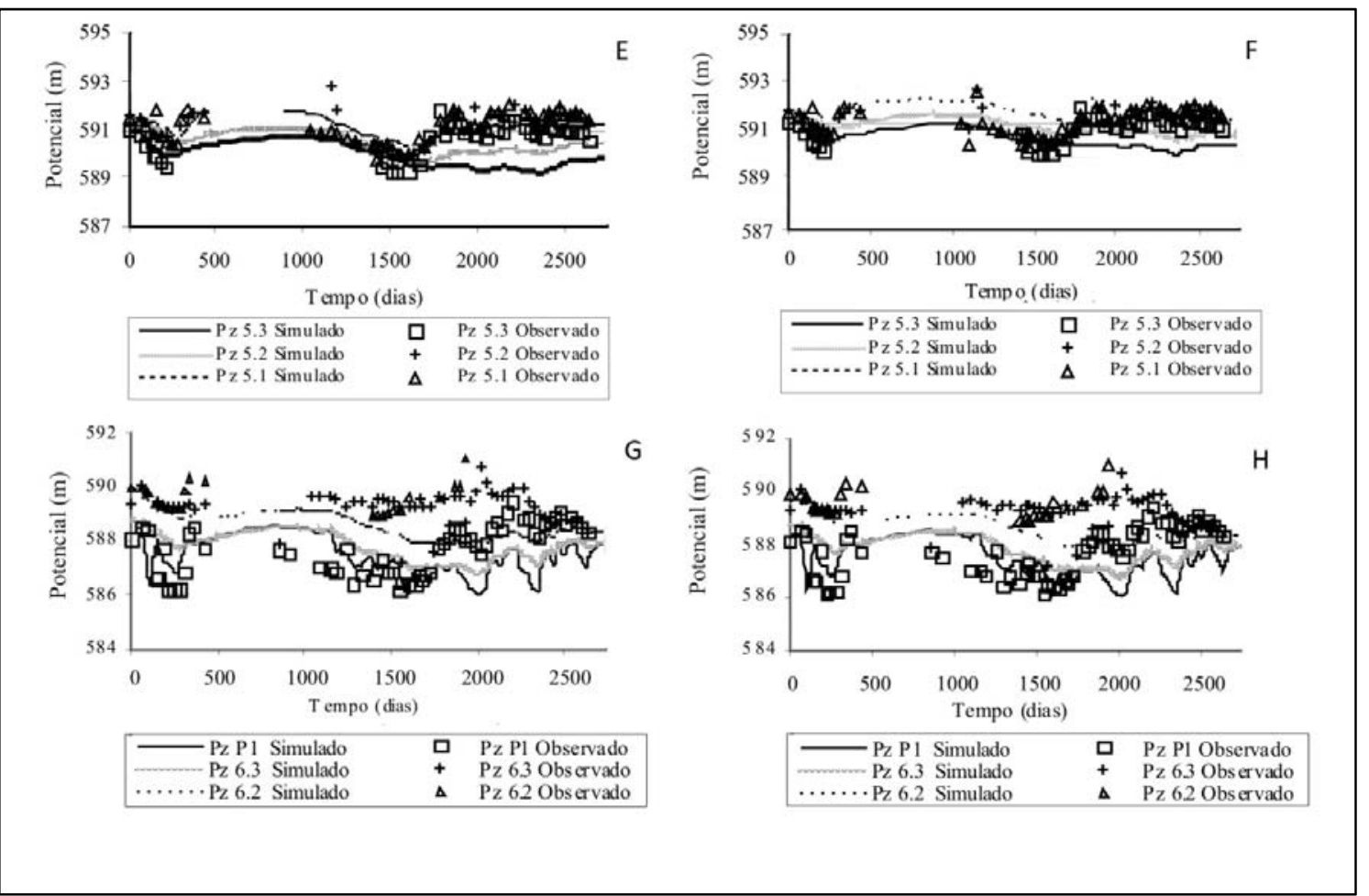

Figura 6. - Potenciometrias simuladas e observadas na face leste do aluvião para os piezômetros sem a inserção do riacho ( $\mathrm{E}$ e G) e na presença da contribuição hídrica do riacho (F e H) 


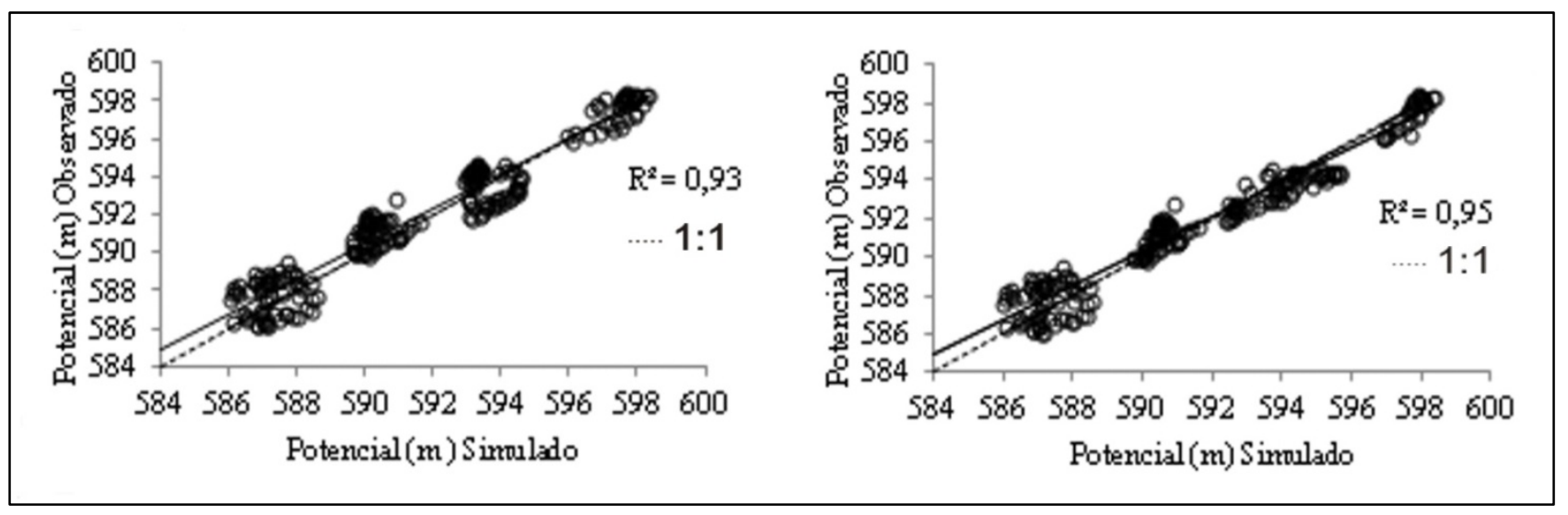

Figura 7 - Grau de associação entre valores medidos e simulados do potencial hidráulico sem inserção do riacho (A) e com inserção do riacho $(B)$

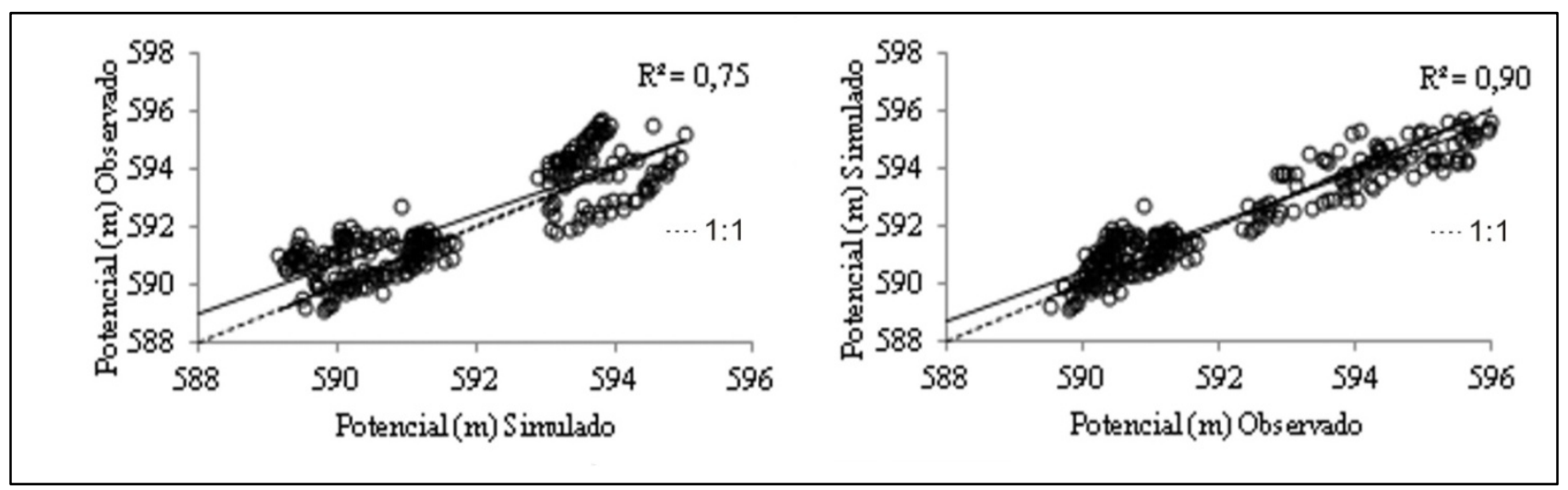

Figura 8 - Grau de associação entre valores medidos e simulados do potencial hidráulico sem inserção do riacho (A) e com inserção do riacho $(B)$, para os piezômetos 3.17, 3.24, 5.1, 5.2 e 5.3 localizados na região central do vale

terização de fluxo entre rio e aquífero. Pode-se, também, afirmar que existe uma correlação entre os valores da descarga no curso de água e o nível do aquífero. A variação do nível do aquífero ocorre de forma relativamente homogênea. Dessa forma, embora influenciado pelas características hidráulicas do meio poroso, como afirmam Gouvêa \& Wendland (2011), o nível do aquífero pode ser representado pelo nível de água em poços de monitoramento localizados no seu eixo longitudinal. As medidas descritivas do grau de associação referente à análise do coeficiente de determinação para todos os piezômetros são apresentadas na Figura 7 e, para os piezômetros centrais, na Figura 8. Nota-se influência da presença do riacho na regulação do nível freático. Em geral, há uma tendência dos aquíferos freáticos drenarem no período seco para o curso de água e serem recarregados no período chuvoso. Gomes \& Frischkorn (2009) observaram a impor- tância da interação rio-aquífero, em especial o Rio Quixeré, no Ceará, que drena as águas do aluvião na estação seca e, durante a estação chuvosa, o rio alimenta os aluviões, cuja perenização (do rio) teria levado o sistema rio-aquífero a entrar em equilíbrio.]

As precisões das estimativas numéricas foram verificadas considerando o erro quadrado médio (EQM), apresentando os valores de 0,74 na presença do rio e 0,89 na ausência do rio, considerando todos os piezômetros distribuídos ao longo do vale aluvial (Figura 7). Na região central do vale, os valores foram de 0,55 na presença do rio e 0,87 na ausência (Figura 8). Tais índices indicam a influência do curso d’água na dinâmica piezométrica na região central do vale. Para critério de concordância, as simulações apresentaram altas concordâncias, em todos os casos $(d=0,99)$. 


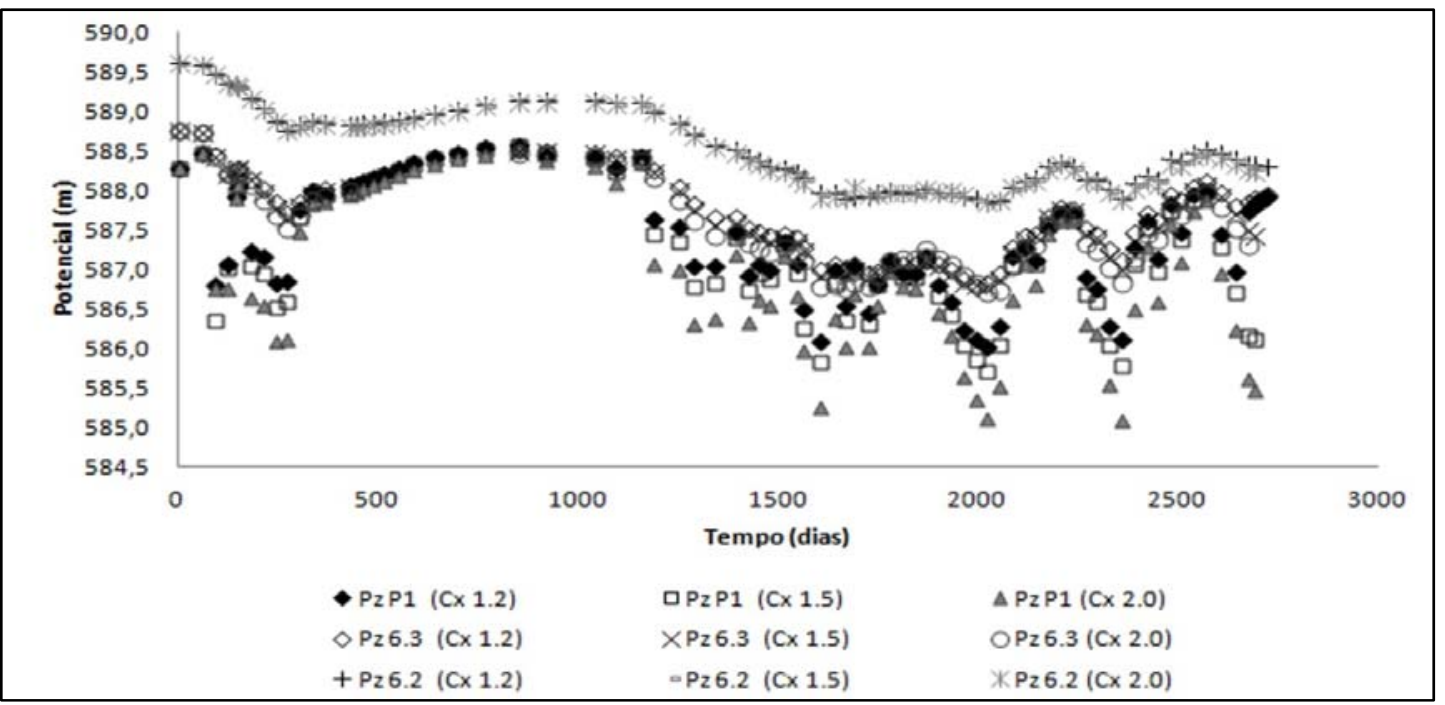

Figura 9 - Potenciais hidráulicos simulados próximo ao contorno de jusante do aluvião, com coeficiente de lixiviação $(\mathrm{Cx})$ de 1,$2 ; 1,5$ e 2,0

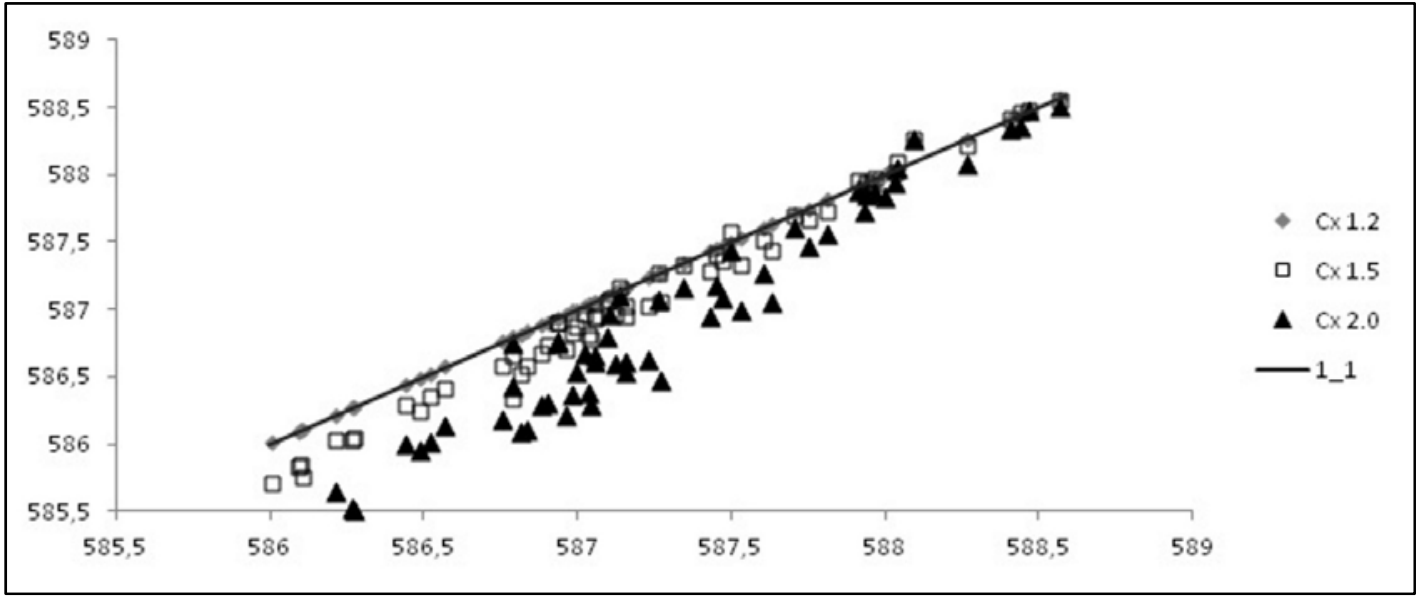

Figura 10 - Grau de associação entre valores agronômicos e coeficiente de lixiviação de 1,2; 1,5 e 2,0

Essas simulações foram realizadas considerando a condição de bombeamento corrente, para atendimento à necessidade hídrica das culturas, não se tendo observado rebaixamentos significativos que pudessem comprometer a piezometria do aluvião.

Cenários de simulação adotando diferentes coeficientes de lixiviação foram testados. A Figuras 9 apresenta cenários de simulação com coeficientes de lixiviação de 1,2; 1,5 e 2,0, próximo ao contorno de jusante. Observa-se que ocorreu maior rebaixamento potenciométrico a partir do dia 1500 durante os períodos de recesso, à medida que se aumenta a lâmina de lixiviação, para alguns piezômetros.
As cargas piezométricas produzidas pelo modelo à jusante da área de estudo, indicam maior dinâmica piezométrica,como esperado. Observa-se que os maiores picos de rebaixamento ocorreram para o piezômetro $\mathrm{P} 1$, localizado próximo ao poço local de maior dinâmica de uso pelos agricultores locais. Nota-se também que as frações de lixiviação influenciam sensivelmente no rebaixamento freático durante o período de recesso hídrico. Em relação ao grau de associação referente ao piezômetro $\mathrm{P} 1$, observa-se que os rebaixamentos mais expressivos ocorrem para os coeficientes de 1,5 e 2,0.

Visualiza-se, na Figura 10 o grau de associação linear entre valores agronômicos e coeficiente 
de lixiviação de 1,2; 1,5 e 2,0. Observa-se que valores de coeficientes de lixiviação acima de 1,2 produzem maior rebaixamento do nível freático.

\section{CONGLUSÕES}

A modelagem apresentou desempenho adequado nas fases de calibração e validação, permitindo a estimativa de taxas de recarga laterais e difusas.

Na condição adotada de bombeamento, não houve rebaixamento significativo que comprometesse o potencial hídrico subterrâneo.

As simulações realizadas com diferentes coeficientes de lixiviação, e em região crítica do vale em termos de rebaixamento, possibilitaram verificar o elevado potencial do aquífero para suportar incrementos nas taxas de bombeamento, em particular para coeficiente de lixiviação de 1,2.

\section{AGRADECIMENTOS}

Os autores agradecem ao CNPq/FINEP CTHIDRO por financiamento de projetos de pesquisa que proporcionaram a coleta dos dados e ao Instituto Nacional de Meteorologia (INMET) pelo fornecimento dos dados pluviométricos.

\section{REFERÊNCIAS}

ARANTES, E. J., CHAUDHRY, F. H., MARCUSSI, F. F. N. Caracterização da interação entre rio e aqüífero com o uso de infiltrômetros. Águas Subterrâneas, v.20, n.2, p.97-108, 2006.

ARBAT, G., PUIG-BARGUÉSM, J., BARRAGÁN, J., BONANY, J., CARTAGENA, R. DE F. Monitoring soil water status for micro-irrigation management versus modelling approach. Biosystems Engineering, V. 100, Issue 2, p. 286-296, 2008.

ALVES, E. M.; NETTO, ANDRÉ MACIEL ; ANTONINO, A. C. D. ; LIMA, J. R. S. ; SOUZA, E. S. ; MONTENEGRO, S. M. G. L. ; CABRAL, J. J. S. P. ; GONDIM, M. V. S. . Simulação da Dinâmica da Água em Solo Cultivado com Feijão Caupi no Brejo Paraibano. Revista Brasileira de Recursos Hídricos, v. 17, p. 175-186, 2012.

BASTOS, D. C. DE O.; MONTENEGRO, A. A. DE A.; MONTENEGRO, S. M. G. L. Avaliação de Alternativa de Irrigação Suplementar com Água Moderadamente Salina em Vale Alu- vial no Semi-Árido: Experimentação e Modelagem. Revista Brasileira de Recursos Hídricos, v.14, n.3, p.27-36, 2009.

BATISTA, M. L. DE C.; REGO, J, C,; RIBEIRO, M. M. R.; ALBUQUERQUE, J. DO P T. Modelagem do fluxo subterrâneo na Bacia Sedimentar Costeira do Baixo Curso do Rio Paraíba como subsídio à Gestão de Recursos Hídrico. Revista Brasileira de Recursos Hídricos, v.16, n.3, p.163-175, 2011.

BLACKBURN, D. N, Efeito da drenagem subterrânea no balanço hidrossalino de um Neossolo flúvico irrigado em Pesqueira/PE. Recife: Universidade Federal Rural de Pernambuco. 2002. 98p. Dissertação Mestrado

BORSI, I.; ROSSETTO, R.; SCHIFANI C.; HILL, M. C. Modeling unsaturated zone flow and runoff processes by integrating MODFLOW-LGR and VSF, and creating the new CFL package Journal of Hydrology v.488 p.33-47. 2013

BURTE J.; JAMIN J. Y.; COUDRAIN A.; FRISCHKORN H.; MARTINS E.S. Simulations of multipurpose water availability in a semi-arid catchment under different management strategies. Agricultural Water Management, v.96 n.8, p. 1181-1190, 2009.

DOORENBOS, J.; PRUITT, W.O. Necessidades hídricas das culturas. Tradução de GHEYI, H. et al. Campina Grande: UFPB, 1997. 204 p. (Estudos FAO: Irrigação e Drenagem, 24).

FONTES JUNIOR, R. V. P. ; MONTENEGRO, A. A. A. ; MONTENEGRO, SUZANA M. G. L.; SANTOS, T. E. M. Estabilidade temporal da potenciometria e da salinidade em vale aluvial no semiárido de Pernambuco. Revista Brasileira de Engenharia Agrícola e Ambiental (Online), v. 16, p. 1188-1197, 2012.

FURMAN, A., Modeling coupled surface-subsurface flow processes: a review. Vadose Zone Journal v.7, p.741-756. 2008.

GOMES, D.; FRISCHKORN, F. H. Aspectos da hidrodinâmica do aquífero aluvial do Rio Jaguaribe, em Limoeiro do Norte Ceará. Águas Subterrâneas, v.23, n.01, p.45-68. 2009.

GOUVÊA, T. H.; WENDLAND, E. C. Influência de Características do Solo na Variação do Nível d'água em Região de Recarga do Aquífero Guarani, Revista Brasileira de Recursos Hídricos, v. 16 n.1, p. 55-65, 2011.

GUIGUER, N. JR.; FRANZ, T. User's for Manual for Visual MODFLOW, Versão 2.2. Waterloo Hydrogeologic Inc. Ontário Canada. 1996. 231p.

LIMA, C.H.R.; FRISCHKORN, H.; BURTE, J. Avaliação da interação rio-aquífero a partir de dados experimentais e de um 
modelo analítico. Revista Brasileira de Recursos hídricos, v.12, n.1, p.217-230, jan/mar 2007.

MACDONALD, M. G.; HARBAUGH, A. W. A Modular Threedimensional Finite-difference Ground Water Flow Model, U.S. Geological Survey, Open File Report p.83-875. 1984.

MONTENEGRO, A. A. A. Stochastic Hydrologeological Modelling of Aquifer Salinization from Small Scale Agriculture in Northeast Brasil. Department of Civil Engineering. University of Newcastle. UK. 1997. PH. D. Thesis.

MONTENEGRO, A. A. A.; MONTENEGRO, S. M. G. L. Variabilidade espacial de classes de textura, salinidade e condutividade hidráulica de solos em planície aluvial. Revista Brasileira de Engenharia Agrícola, v.10, p.30-37. 2006.

OLSTHOORN T.N. A comparative review of analytic and finite models used at the Amsterdam Water Supply. Journal of Hydrology. v.226, p.139- 143. 1999

PANAGOPOULOS, G. Application of MODFLOW for simulating groundwater flow in the Trifilia karst aquifer, Greece. Environ Earth Science v.67 p.1877-1889. 2012

RASSAM, D.W. A conceptual framework for incorporating surfaceegroundwater interactions into a river operatione planning model, Environmental Modelling \& Software, v.26, n.12, p.1554-1567, 2011.

RIBEIRO, M. R.; CORRÊA, M. M. Levantamento detalhado de solos da Fazenda Nossa Senhora do Rosário. In: Montenegro, A. A. A. Diagnóstico e controle da salinização em aluviões com pequena agricultura irrigada. Recife: UFRPE, Relatório de Projeto CNPq- Programa Nordeste, processo número 521224/98-5, 2001.

RUSHTON, K, Representation in regional models of saturated river-aquifer interaction for gaining/losing rivers, Journal of Hydrology, v.334 n1-2 p.262-281, 2007.

SANTIAGO, F. S.; MONTENEGRO, A.A.A.; MONTENEGRO, S.M.G.L. Avaliação de parâmetros hidráulicos e manejo da irrigação por microaspersão em área de assentamento. Engenharia Agrícola, Jaboticabal, v.24, n.3, p.632-643, 2004.

SANTOS, F. X.; MONTENEGRO, A. A. A.; SILVA, J. R.; SOUZA, E. R. Determinação do consumo hídrico da cenoura utilizando lisímetros de drenagem, no agreste pernambucano.
Revista Brasileira de Ciências Agrárias. Recife, v.4, n.3, p.304310, 2009.

SOPHOCLEOUS, M. Interactions between groundwater and surface water: the state of the science. Hydrogeology Journal, v.10 n.1 p.52-67. 2002.

WINSTON R.B. MODFLOW - Related freeware and shareware resources on the internet. Computer \& Geosciences. v.25 p.377-382. 1999.

XU, X.; HUANG, G H.; QU, Z Y. Integrating MODFLOW and GIS technologies for assessing impacts of irrigation management and groundwater use in the Hetao Irrigation District, Yellow River basin. Science China Series. ETechnological Sciences, v.52, n.11 p.3257-3263. 2009.

\section{Modeling Flow And Assessment Of Water Potential Of Alluvial Aquifer In The Semiarid Of Pernambuco}

\section{ABSTRACT}

This work was developed in an alluvial valley used for small irrigation, with the aim of evaluating its hydraulic potential under its current exploitation condition and the relevance of river-aquifer interaction even in the dry season. Using MODFLOW software the flow and water potential distribution in the valley were evaluated, considering land use. To calibrate and validate the model, it was assumed that the aquifer extractions followed agronomic criteria, based on crop water uptake. Scenarios with different leaching fractions (20\%, 50\% and $100 \%)$ were evaluated to investigate the effect of additional extractions on the aquifer potentiometric level, and its influence on lowering the water table, especially during the recession period. Besides, diffuse fluxes at the soil surface (recharge and evaporation) were considered, and the contributions from the surrounding watershed. The importance of river-aquifer interaction over the aquifer potentiometric levels was observed, and it was found that the alluvial aquifer is subjected to high recharge rates, so that pumping rates applied do not endanger sustainability.

Key words: Irrigated agriculture, groundwater, riveraquifer interaction 